\title{
A Retrospective Comparison of Interscalene Continuous Catheter Verse Single-Injection with Liposomal Bupivacaine in Total Shoulder Arthroplasty
}

\author{
Benjamin J. Kenny, Emily S. Schmidt, Amy W. Wozniak, Scott W. Byram* \\ Department of Anesthesiology and Perioperative Medicine, Loyola University, Chicago, IL, USA \\ Email: *sbyram@lumc.edu
}

How to cite this paper: Kenny, B.J., Schmidt, E.S., Wozniak, A.W. and Byram, S.W. (2021) A Retrospective Comparison of Interscalene Continuous Catheter Verse Single-Injection with Liposomal Bupivacaine in Total Shoulder Arthroplasty. Open Journal of Anesthesiology, 11, 269-278.

https://doi.org/10.4236/ojanes.2021.119026

Received: July 29, 2021

Accepted: September 4, 2021

Published: September 7, 2021

Copyright $\odot 2021$ by author(s) and Scientific Research Publishing Inc. This work is licensed under the Creative Commons Attribution International License (CC BY 4.0).

http://creativecommons.org/licenses/by/4.0/

(c) (i) Open Access

\begin{abstract}
Background: One common method of pain control for total shoulder arthroplasty is long-duration delivery of local anesthetic via interscalene brachial plexus block (ISB) with a continuous catheter. Alternatively, liposomal bupivacaine has also been administered as an ISB as a means to prolong the analgesic effect. This study was completed to measure the non-inferiority of single-injection ISB with liposomal bupivacaine compared with ISB continuous catheter for total shoulder arthroplasty. Methods: We performed a retrospective chart review of patients who underwent total shoulder arthroplasty using either an ISB continuous catheter or a single injection ISB with liposomal bupivacaine for post operative analgesia. The primary goal of this study was to determine if single-injection with liposomal bupivacaine conferred non-inferior pain scores compared to the continuous catheter. Secondary outcomes evaluated oxygen saturation as a measure of hemidiaphragmatic paresis, post operative opioid requirements, and difference in cost. Results: We identified 333 patients for the study: 126 received continuous catheter and 207 received single-injection with liposomal bupivacaine. The median length of stay was 1 day. Pain scores for those treated with single-injection with liposomal bupivacaine were non-inferior to pain scores of those treated with the continuous catheter on post-op days 0,1 and 2. Pain scores were lower for single-injection with liposomal bupivacaine patients on days 3 and 4, however they did not reach statistical significance. There was no significant difference in oxygen saturation between the two groups. Both groups had similar daily morphine milligram equivalent requirements. Liposomal bupivacaine ISB was also found to be less expensive. Conclusion: Single-injection ISB with liposomal bupivacaine provides non-inferior analgesia at a reduced cost compared with continuous catheter ISB for total shoulder arthroplasty.
\end{abstract}




\section{Keywords}

Regional Anesthesia, Interscalene Nerve Block, Total Shoulder Arthroplasty, Liposomal Bupivacaine, Continuous Catheter, Peri-Operative Analgesia

\section{Introduction}

Liposomal Bupivacaine (LB) was introduced to the market in early 2012 as a novel formulation of bupivacaine that could be effective for pain management up to 72 hours following single-dose administration. Early studies demonstrated conflicting results on the efficacy of LB. These studies often compared liposomal bupivacaine infiltration at the surgical site or intra-articular to peripheral nerve catheters, [1] [2] [3] [4] which are two techniques that do not provide the same analgesia. At our institution, single-injection blocks with LB have become the preferred method of regional anesthesia over indwelling catheters. This change reflected some early studies demonstrating positive results when comparing the two techniques [5]. Additionally, on a very busy service, we found that single-injection blocks with LB allowed faster placement and less nursing care and follow-up compared with a catheter technique. Those early studies comparing LB use in differing techniques were misleading and diverged from what was observed clinically after we changed to Single-Injections with LB (SILB). Over time, newer studies have been conducted to compare LB to continuous catheters in regard to equivalent techniques. One recently published study examined LB with interscalene brachial plexus blocks (ISB) versus Interscalene Continuous Catheters (ISCC) for shoulder arthroplasties and showed that LB produced lower opioid consumption and improved pain scores [6].

The ISB is a well-established, regularly utilized, regional technique that provides excellent perioperative pain control in Total Shoulder Arthroplasty (TSA) [7] [8]. Furthermore, extending that pain control over a longer period post operatively with a catheter provides additional benefits as has been borne out in previous studies [9] [10] [11] [12]. TSA has progressively increased in frequency in both the inpatient and ambulatory settings [13]. Therefore, using a SILB technique to provide prolonged blockade rather than a catheter technique could allow for greater efficiency if the block quality is not sacrificed.

ISBs are associated with complications including high-incidence ipsilateral hemidiaphragmatic paresis, as well as Horner's syndrome and to a lesser extent recurrent laryngeal nerve paresis [14] [15] [16]. Catheters are associated with their own specific complications including displacement, obstruction, patient discomfort, increased infection risk, and prolonged effect of known/expected complications [10] such as phrenic nerve paresis. Yet all of these potential negatives are still outweighed by providing appropriate post operative pain control and decreasing negative outcomes such as readmissions for a significantly painful surgery [17]. 
The goal of this study was to determine non-inferiority of SILB compared to ISCC with plain ropivacaine infusion by measuring patient pain scores while additionally measuring post operative opioid requirements and oxygen saturation as a measure of phrenic nerve paresis as secondary outcomes. Additionally, the cost between the two modalities was compared because LB has a high initial cost, but minimal-to-no downstream the cost. By using LB, one avoids the cost of the kit, local anesthetic infusion, and follow-ups associated with catheters. The compiled data were evaluated for non-inferiority of SILB to the more common ISCC.

\section{Methods}

A retrospective chart review was conducted on patients who received a TSA by the same two fellowship trained surgeons at a single institution in an inpatient setting between January 1, 2008 and August 1, 2018. IRB approval was obtained and the data collected included basic patient identifiers (age, gender, BMI, ASA status), pain scores throughout the perioperative period, oxygen saturation and supplementation, and amount of postoperative opioids required. If a patient had multiple surgeries, only the first surgery was used. The nerve blocks were completed under ultrasound guidance by the same team of anesthesiologists directly overseeing residents executing the procedure both prior to and after changing to LB. The change to LB was immediate with all ISBs completed using LB rather than catheters. The surgical, anesthetic, and post-surgical management were not altered after the change to LB for these blocks. For both SILB and ISCC, the blocks were completed in pre-op holding and all patients received general anesthesia with endotracheal tube.

Pain was charted either on a scale of 0 to 10 or as "No Pain", "Mild", "Moderate", "Severe" depending on the individual nurse caring for each patient. "No Pain" indicated 0; "Mild" indicated 1 - 3; "Moderate" indicated 4 - 6; and "Severe" indicated 7 - 10. If pain was measured in a categorical manner, the midpoint of the scale was used as a numeric imputation for analysis. If a patient had multiple pain measures per day, the average pain score was used. There were no standard times each day that the pain measurements were recorded by the nurses nor was there a standard protocol used to provide "as needed" pain control. Data was gathered until the patients left the hospital or up to post-op day 5 and no further follow up occurred. Other outcomes of interest include oxygen saturation and post operative opioid requirements. For the opioid medications, all were put into Morphine Milligram Equivalences (MME) for comparisons.

The primary goal of this study was to determine if SILB pain control had non-inferior pain scores compared to ISCC pain control. Pain scores within 1 point were deemed as non-inferior. One-sided t-test was used to determine non-inferiority. General descriptive statistics (means, standard deviations, frequencies, medians, quartiles) were used to summarize patient characteristics for the entire cohort and separately for each treatment group. Student's t-test was used to compare continuous characteristics and Chi-square test or Fisher's exact 
test were used to compare categorical characteristics. Other outcomes of oxygen saturation and pain medications were compared using student's t-test and Fisher's exact test. Due to the skewness of LOS and MME data, a non-parametric Wilcoxon test was used for comparisons. Costs for each procedure were determined using values provided by the pharmacy department for individual components used for each procedure, physician billing, and average follow-up needed for each individual.

\section{Results}

We identified 333 patients for the study; 126 received ISCC and 207 received SILB. The average age of the patients was 65.3 years, $42 \%$ male and $82 \%$ white. The median LOS was 1 day (Q1, Q3: 1, 2; Total Range: 1 - 6, Table 1). There were significantly more ASA 4 physical status classification patients in the ISCC group than those with SILB pain control (60\% vs $26 \%$, respectively, $\mathrm{p} \leq 0.001$; Table 1). Our analysis deemed that pain scores for those treated with SILB were non-inferior to pain scores of those treated with ISCC on post-op days 0,1 and 2 (Table 2, Figure 1). Pain scores were lower for SILB patients on days 3 and 4, but they did not reach statistical significance.

There were no significant differences in oxygen saturation between the groups on any of the days (Table 3). Those with SILB pain control had a lower percentage of individuals who needed both opioid and non-opioid pain control on all days (Table 4). SILB and ISCC groups had similar median daily MME (Table 5).

Summation of costs for each procedure resulted in approximately $\$ 763$ dollars saved by performing SILB compared to ISCC (Table 6).

Table 1. Patient characteristics.

\begin{tabular}{|c|c|c|c|c|}
\hline Patient Characteristics & All, $N=333$ & SILB, $N=207$ & ISCC, $N=126$ & P-Value ${ }^{a}$ \\
\hline Age, Mean (SD) & $65.32(11.3)$ & $64.76(11.45)$ & $66.23(11.03)$ & 0.251 \\
\hline Male, $\mathrm{n}(\%)$ & $141(42)$ & $91(44)$ & $50(40)$ & 0.443 \\
\hline White, n (\%) & $273(82)$ & $170(82)$ & $103(82)$ & 0.930 \\
\hline Hispanic, n (\%) & $38(11)$ & $23(11)$ & $15(12)$ & 0.825 \\
\hline BMI, Mean (SD) & $31.98(7.17)$ & $31.7(6.52)$ & $32.46(8.14)$ & 0.381 \\
\hline ASA & & & & $<0.001$ \\
\hline 1 & $7(2)$ & $5(3)$ & $2(2)$ & \\
\hline 2 & $89(29)$ & $67(34)$ & $22(20)$ & \\
\hline 3 & $91(30)$ & $72(37)$ & $19(18)$ & \\
\hline 4 & $116(38)$ & $51(26)$ & $65(60)$ & \\
\hline LOS, Median $(\mathrm{Q} 1, \mathrm{Q} 3)^{\mathrm{b}}$ & $1(1,2)$ & $1(1,2)$ & $1(1,2)$ & 0.413 \\
\hline
\end{tabular}


Table 2. Pain by post-op day.

\begin{tabular}{|c|c|c|c|c|}
\hline Post Op Day 0 & $\begin{array}{c}\text { All } \\
\mathrm{N}=329\end{array}$ & $\begin{array}{c}\text { SILB } \\
\mathrm{N}=203\end{array}$ & $\begin{array}{c}\text { ISCC } \\
\mathrm{N}=126\end{array}$ & P-Value \\
\hline Any Pain (>0), n (\%) & $87(26 \%)$ & $53(26 \%)$ & $34(27 \%)$ & \\
\hline Average Pain (including 0), Mean (SD) & $1.54(2.86)$ & $1.56(2.89)$ & $1.5(2.83)$ & 0.0022 \\
\hline Post Op Day 1 & $\begin{array}{c}\text { All } \\
\mathrm{N}=326\end{array}$ & $\begin{array}{c}\text { SILB } \\
\mathrm{N}=200\end{array}$ & $\begin{array}{c}\text { ISCC } \\
\mathrm{N}=126\end{array}$ & \\
\hline Any Pain (>0), n (\%) & $191(59 \%)$ & $118(59 \%)$ & $73(58 \%)$ & \\
\hline Average Pain (including 0), Mean (SD) & $2.63(2.81)$ & $2.67(2.78)$ & $2.58(2.89)$ & 0.0025 \\
\hline Post Op Day 2 & $\begin{array}{c}\text { All } \\
\mathrm{N}=113\end{array}$ & $\begin{array}{c}\text { SILB } \\
\mathrm{N}=67\end{array}$ & $\begin{array}{c}\text { ISCC } \\
\mathrm{N}=46\end{array}$ & \\
\hline Any Pain (>0), n (\%) & $90(81 \%)$ & $50(76 \%)$ & $40(89 \%)$ & \\
\hline Average Pain (including 0), Mean (SD) & $4.29(2.89)$ & $3.96(2.87)$ & $4.78(2.88)$ & 0.0006 \\
\hline Post Op Day 3 & $\begin{array}{c}\text { All } \\
\mathrm{N}=49\end{array}$ & $\begin{array}{c}\text { SILB } \\
\mathrm{N}=29\end{array}$ & $\begin{array}{c}\text { ISCC } \\
\mathrm{N}=\mathbf{2 0}\end{array}$ & \\
\hline Any Pain (>0), n (\%) & $33(70 \%)$ & $18(67 \%)$ & $15(75 \%)$ & \\
\hline Average Pain (including 0), Mean (SD) & $3.49(2.95)$ & $3.4(2.87)$ & $3.63(3.12)$ & 0.0851 \\
\hline Post Op Day 4 & $\begin{array}{c}\text { All } \\
\mathrm{N}=26\end{array}$ & $\begin{array}{c}\text { SILB } \\
\mathrm{N}=13\end{array}$ & $\begin{array}{c}\text { ISCC } \\
N=13\end{array}$ & \\
\hline Any Pain $(>0), \mathrm{n}(\%)$ & $16(62 \%)$ & $9(67 \%)$ & $7(54 \%)$ & \\
\hline Average Pain (including 0), Mean (SD) & $3.35(3.14)$ & $3.31(2.81)$ & $3.38(3.55)$ & 0.1999 \\
\hline
\end{tabular}

aP-value comparing SILB and ISCC distributions calculated with 1-sided non-inferiority t-test within 1 point average pain score.

Table 3. Mean (SD) $\mathrm{O}_{2}$ saturation.

\begin{tabular}{ccccc}
\hline & All & SILB & ISCC & P-value $^{\mathrm{a}}$ \\
\hline Day 0 & $96.46(1.94), \mathrm{N}=331$ & $96.36(1.99), \mathrm{N}=205$ & $96.61(1.84), \mathrm{N}=126$ & 0.255 \\
Day 1 & $95.17(2.1), \mathrm{N}=327$ & $95.26(2.18), \mathrm{N}=201$ & $95.02(1.96), \mathrm{N}=126$ & 0.326 \\
Day 2 & $94.84(2.5), \mathrm{N}=113$ & $95.18(2.39), \mathrm{N}=67$ & $94.35(2.6), \mathrm{N}=46$ & 0.082 \\
Day 3 & $94.98(2.21), \mathrm{N}=49$ & $94.69(2.51), \mathrm{N}=29$ & $95.4(1.67), \mathrm{N}=20$ & 0.274 \\
Day 4 & $95.04(2.01), \mathrm{N}=26$ & $95.08(2.22), \mathrm{N}=13$ & $95(1.87), \mathrm{N}=13$ & 0.925 \\
Day 5 & $96(2.06), \mathrm{N}=17$ & $96.33(1.66), \mathrm{N}=9$ & $95.63(2.5), \mathrm{N}=8$ & 0.497 \\
\hline
\end{tabular}

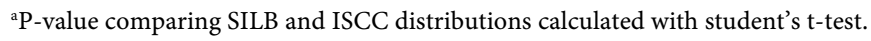

Table 4. Summary of Pain med use.

\begin{tabular}{lcccc}
\hline & All, N = 333 & SILB, N = 207 & ISCC, N = 126 & P-Value $^{\mathbf{a}}$ \\
\hline Day 0-No meds & $13(4)$ & $13(6)$ & $0(0)$ & 0.001 \\
Day 0-Non Opioids Only & $68(20)$ & $35(17)$ & $33(26)$ & \\
Day 0-Opioids Only & $228(68)$ & $148(71)$ & $80(63)$ & \\
Day 0-Both & $24(7)$ & $11(5)$ & $13(10)$ & \\
\hline
\end{tabular}




\section{Continued}

\begin{tabular}{|c|c|c|c|c|}
\hline & All, $\mathrm{N}=329$ & SILB, N = 203 & ISCC, $\mathrm{N}=126$ & P-Value ${ }^{a}$ \\
\hline Day 1 -No meds & $11(3)$ & $11(5)$ & $0(0)$ & 0.014 \\
\hline Day 1 -Non Opioids Only & $30(9)$ & $16(8)$ & $14(11)$ & \\
\hline Day 1-Opioids Only & $195(59)$ & $124(61)$ & $71(56)$ & \\
\hline \multirow{2}{*}{ Day 1-Both } & $93(28)$ & $52(26)$ & $41(33)$ & \\
\hline & All, $N=116$ & SILB, $N=70$ & ISCC, $\mathrm{N}=46$ & P-Value ${ }^{a}$ \\
\hline Day 2-No meds & $2(2)$ & $2(3)$ & $0(0)$ & 0.523 \\
\hline Day 2-Non Opioids Only & $5(4)$ & $3(4)$ & $2(4)$ & \\
\hline Day 2-Opioids Only & $59(51)$ & $38(54)$ & $21(46)$ & \\
\hline \multirow[t]{2}{*}{ Day 2-Both } & $50(43)$ & $27(39)$ & $23(50)$ & \\
\hline & All, $\mathrm{N}=54$ & SILB, $N=32$ & ISCC, $\mathrm{N}=22$ & P-Value \\
\hline Day 3-No meds & $1(2)$ & $1(3)$ & $0(0)$ & 0.025 \\
\hline Day 3-Non Opioids Only & $7(13)$ & $7(22)$ & $0(0)$ & \\
\hline Day 3-Opioids Only & $19(35)$ & $12(38)$ & $7(32)$ & \\
\hline \multirow[t]{2}{*}{ Day 3-Both } & $27(50)$ & $12(38)$ & $15(68)$ & \\
\hline & All, $\mathrm{N}=30$ & SILB, $N=26$ & ISCC, $\mathrm{N}=14$ & P-Value \\
\hline Day 4-Non Opioids Only & $3(10)$ & $2(13)$ & $1(7)$ & 0.217 \\
\hline Day 4-Opioids Only & $11(37)$ & $8(50)$ & $3(21)$ & \\
\hline \multirow[t]{2}{*}{ Day 4-Both } & $16(53)$ & $6(38)$ & $10(71)$ & \\
\hline & All, $\mathrm{N}=22$ & SILB, $N=12$ & ISCC, $\mathrm{N}=10$ & P-Value \\
\hline Day 5-Non Opioids Only & $3(14)$ & $2(17)$ & $1(10)$ & 0.107 \\
\hline Day 5-Opioids Only & $9(41)$ & $7(58)$ & $2(20)$ & \\
\hline Day 5-Both & $10(45)$ & $3(25)$ & $7(70)$ & \\
\hline
\end{tabular}

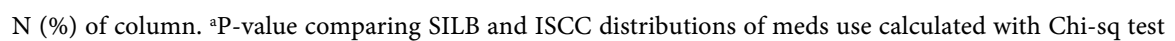
or Fisher's exact test.

Table 5. Daily opioid use in morphine milligram equivalences.

\begin{tabular}{lcccc}
\hline & All patients & SILB & ISCC & P-Value \\
\hline $\begin{array}{l}\text { Day 0, } \\
\text { Median (Q1, Q3) }\end{array}$ & $4(0,9), \mathrm{N}=333$ & $4(2,10), \mathrm{N}=207$ & $4(0,7.5), \mathrm{N}=126$ & 0.102 \\
Day 1, & $12(4,20), \mathrm{N}=329$ & $12(4,20), \mathrm{N}=203$ & $9(4,16), \mathrm{N}=126$ & 0.318 \\
Median (Q1, Q3) & & & & 0.766 \\
$\begin{array}{l}\text { Day 2, } \\
\text { Median (Q1, Q3) }\end{array}$ & $14(8,24), \mathrm{N}=116$ & $12(8,28), \mathrm{N}=70$ & $16(10,24), \mathrm{N}=46$ & \\
$\begin{array}{l}\text { Day 3, } \\
\text { Median (Q1, Q3) }\end{array}$ & $13(4,24), \mathrm{N}=54$ & $12(0,27.5), \mathrm{N}=32$ & $16(8,24), \mathrm{N}=22$ & 0.485 \\
$\begin{array}{l}\text { Day 4, } \\
\text { Median (Q1, Q3) }\end{array}$ & $13(4,24), \mathrm{N}=30$ & $10(4.5,28), \mathrm{N}=16$ & $15(4,18), \mathrm{N}=14$ & 0.692 \\
$\begin{array}{l}\text { Day 5, } \\
\text { Median (Q1, Q3) }\end{array}$ & $8(2,24), \mathrm{N}=22$ & $18(2,32), \mathrm{N}=12$ & $7(2,14), \mathrm{N}=10$ & 0.354 \\
\hline
\end{tabular}

a P-value comparing SILB and ISCC distributions calculated with Wilcoxon test. 
Table 6. Total shoulder arthroplasty costs.

\begin{tabular}{cccc}
\hline $\begin{array}{c}\text { Single-Injection with Liposomal Bupivacaine } \\
\text { (SILB) }\end{array}$ & \multicolumn{2}{c}{ Single-Injection Continuous Catheter (ISCC) } \\
\hline Block needle & $\$ 11.76$ & Epidural kit & $\$ 24.26$ \\
10 cc 0.5\% Bupivacaine & $\$ 54.18$ & Pump tubing & $\$ 7.12$ \\
10cc 1.3\% LB & $\$ 180.35$ & Ropivacaine 0.2\% 1500 cc (for 2 days) & $\$ 259.84$ \\
Physician procedure bill & $\$ 869.00$ & Physician procedure bill & $\$ 1345.00$ \\
& & Physician follow-up (2 days) & $\$ 484.00$ \\
Total & $\$ 1115.29$ & Total & $\$ 1878.22$ \\
\hline
\end{tabular}

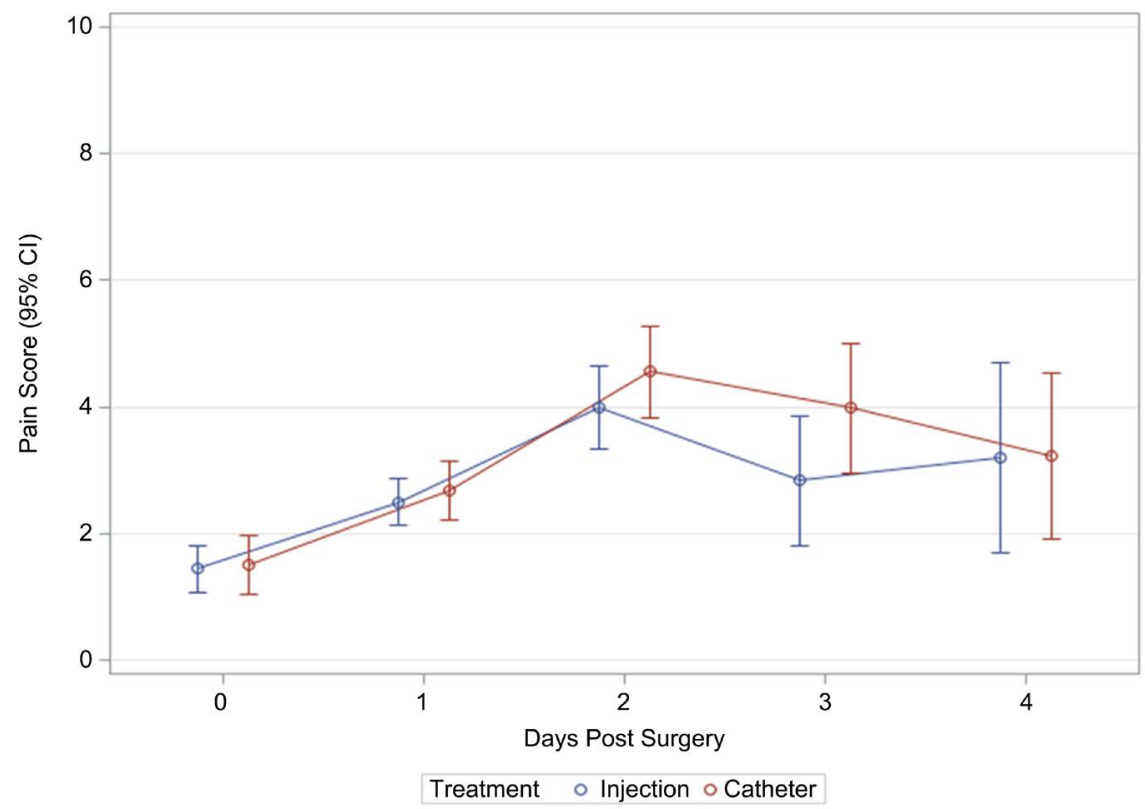

Figure 1. Pain by post-op day.

\section{Discussion}

The data showed that SILB pain scores were significantly non-inferior to ISCC for days 0 - 2 and were lower on days 3 and 4, but did not reach non-inferior threshold for significance. The patient sample size on days 3 and 4 was insufficient to provide an appropriate comparison to days $0-2$ due to patient discharges on day 2. These findings make sense since both techniques deliver local anesthetic to the brachial plexus for multiple days. Additionally, hemidiaphragmatic paresis, which can result in decreased ventilation to the ipsilateral lung was monitored by oxygen saturation, were not significantly different between the two techniques and both groups used similar amounts of MME. The single-injection group did show a trend of less pain medications used however this was not statistically significant. In this study, the median length of stay was 1 day (Q1, Q3: $1,2)$ regardless of SILB or ISCC procedure.

Cost analysis revealed a lower cost to perform SILB than ISCC as illustrated by Table 6. The primary difference in cost comes from the more involved (higher ASA unit) procedure and from the two follow-up days associated with conti- 
nuous catheters. This data supports the use of LB in standard perioperative scenarios as the pain control and perioperative MME are similar to continuous catheters while the cost and resource use are lower.

Considering these results and accounting for the time and cost difference between the two studied techniques, LB appears to have significant upside. Conversely, there are clear potential downsides to LB use in peripheral nerve bocks primarily related to lack of titratability. With a catheter, any side effects such as phrenic nerve paresis, Horner's syndrome, or undesired motor block could be more quickly abated by decreasing or stopping the infusion. With a LB block there is no "off button"; the physician and patient must simply wait for the LB to wear off. In most patients these complications are not life-threatening and can be tolerated. In instances that a side effect, such as phrenic nerve paresis, could cause significant health complications, then neither technique would likely be appropriate, and a different block or perioperative pain plan would need to be devised. An additional limitation of using LB is the inability to perform rescue blocks within 96 hours after LB administration if the physician follows the manufacturer's guidelines [18]. Another important consideration is the patient populations for whom LB would not be the ideal regional technique to utilize. For example, in burn patients or poly-orthopedic trauma patients who regularly have long hospital courses with repeated surgical procedures the flexibility of a catheter or multiple single injection blocks with plain bupivacaine would be superior.

The primary limitation of this study was that it was a retrospective chart review rather than a prospective trial. Additionally, the use of oxygen saturation is a less sensitive measure of hemidiaphragmatic paresis compared to bedside ultrasound or chest X-ray. However, oxygen utilization may be more clinically relevant. Another limitation was the lack of follow up with patients discharged prior to post-op day three; this would have provided a better picture of pain control over the maximum expected duration of LB. Finally, the retrospective nature of the study caused heterogeneity in the post operative pain medication regimen, leading to variation in multimodal pain medication administered postoperatively, possibly affecting opioid requirements. Additional large prospective randomized controlled trials would further help to establish the role of LB use with brachial plexus blocks for sustained postoperative analgesia in total shoulder arthroplasty.

\section{Conclusion}

Single-injection interscalene blocks with liposomal bupivacaine were non-inferior to continuous catheters for patients receiving a total shoulder arthroplasty. Additionally, single-injection with liposomal bupivacaine was not associated with additional complications such as phrenic nerve paresis as compared to continuous catheters. MME use was similar between the two groups and single-injection reduces cost. This study demonstrates that regular use of liposomal bupivacaine in 
interscalene brachial plexus blocks would result in similar analgesic outcomes and complication frequency with less financial impact to the patient and institution, decreased infection risk, and quicker procedure time.

\section{Conflicts of Interest}

The authors declare no conflicts of interest regarding the publication of this paper.

\section{References}

[1] Namdari, S., Nicholson, T., Abboud, J., Lazarus, M., Steinberg, D. and Williams, G. (2017) Randomized Controlled Trial of Interscalene Block Compared with Injectable Liposomal Bupivacaine in Shoulder Arthroplasty. The Journal of Bone and Joint Surgery. American Volume, 99, 550-556. https://doi.org/10.2106/JBJS.16.00296

[2] Abildgaard, J.T., Lonergan, K.T., Tolan, S.J., Kissenberth, M.J., Hawkins, R.J., Washburn, R., et al. (2017) Liposomal Bupivacaine versus Indwelling Interscalene Nerve Block for Postoperative Pain Control in Shoulder Arthroplasty: A Prospective Randomized Controlled Trial. Journal of Shoulder and Elbow Surgery, 26, 1175-1181. https://doi.org/10.1016/j.jse.2017.03.012

[3] Namdari, S., Nicholson, T., Abboud, J., Lazarus, M., Steinberg, D. and Williams, G. (2018) Interscalene Block with and without Intraoperative Local Infiltration with Liposomal Bupivacaine in Shoulder Arthroplasty: A Randomized Controlled Trial. The Journal of Bone and Joint Surgery, 100, 1373-1378.

https://doi.org/10.2106/JBJS.17.01416

[4] Sabesan, V.J., Shahriar, R., Petersen-Fitts, G.R., Whaley, J.D., Bou-Akl, T., Sweet, M., et al. (2017) A Prospective Randomized Controlled Trial to Identify the Optimal Postoperative Pain Management in Shoulder Arthroplasty: Liposomal Bupivacaine versus Continuous Interscalene Catheter. Journal of Shoulder and Elbow Surgery, 26, 1810-1817. https://doi.org/10.1016/i.jse.2017.06.044

[5] Weller, W.J., Azzam, M.G., Smith, R.A., Azar, F.M. and Throckmorton, T.W. (2017) Liposomal Bupivacaine Mixture Has Similar Pain Relief and Significantly Fewer Complications at Less Cost Compared to Indwelling Interscalene Catheter in Total Shoulder Arthroplasty. The Journal of Arthroplasty, 32, 3557-3562.

https://doi.org/10.1016/j.arth.2017.03.017

[6] Weir, T.B., Simpson, N., Aneizi, A., Foster, M.J., Jauregui, J.J., Gilotra, M.N., et al. (2020) Single-Shot Liposomal Bupivacaine Interscalene Block versus Continuous Interscalene Catheter in Total Shoulder Arthroplasty: Opioid Administration, Pain Scores, and Complications. Journal of Orthopaedics, 22, 261-267.

https://doi.org/10.1016/j.jor.2020.05.006

[7] Shah, A., Nielsen, K.C., Braga, L., Pietrobon, R., Klein, S.M. and Steele, S.M. (2007) Interscalene Brachial Plexus Block for Outpatient Shoulder Arthroplasty: Postoperative Analgesia, Patient Satisfaction and Complications. Indian Journal of Orthopaedics, 41, 230-236. https://doi.org/10.4103/0019-5413.33688

[8] Ilfeld, B.M., Vandenborne, K., Duncan, P.W., Sessler, D.I., Enneking, F.K., Shuster, J.J., et al. (2006) Ambulatory Continuous Interscalene Nerve Blocks Decrease the Time to Discharge Readiness after Total Shoulder Arthroplasty: A Randomized, Triple-Masked, Placebo-Controlled Study. Anesthesiology, 105, 999-1007. https://doi.org/10.1097/00000542-200611000-00022

[9] Gomide, L.C., Ruzi, R.A., Mandim, B.S., Dias, V.A.D.R. and Freire, R.H.D. (2018) Prospective Study of Ultrasound-Guided Peri-Plexus Interscalene Block with Con- 
tinuous Infusion Catheter for Arthroscopic Rotator Cuff Repair and Postoperative Pain Control. Revista Brasileira de Ortopedia, 53, 721-727. https://doi.org/10.1016/j.rboe.2017.08.020

[10] Hasan, S.S., Rolf, R.H., Sympson, A.N., Eten, K. and Elsass, T.R. (2019) Single-Shot versus Continuous Interscalene Block for Postoperative Pain Control after Shoulder Arthroplasty: A Prospective Randomized Clinical Trial. Journal of the American Academy of Orthopaedic Surgeons. Global Research and Reviews, 3, e014. https://doi.org/10.5435/JAAOSGlobal-D-19-00014

[11] Bojaxhi, E., Lumermann, L.A., Mazer, L.S., Howe, B.L., Ortiguera, C.J. and Clendenen, S.R. (2019) Interscalene Brachial Plexus Catheter versus Single-Shot Interscalene Block with Periarticular Local Infiltration Analgesia for Shoulder Arthroplasty. Minerva Anestesiologica, 85, 840-845. https://doi.org/10.23736/S0375-9393.19.13387-1

[12] Vorobeichik, L., Brull, R., Bowry, R., Laffey, J.G. and Abdallah, F.W. (2018) Should Continuous Rather than Single-Injection Interscalene Block Be Routinely Offered for Major Shoulder Surgery? A Meta-Analysis of the Analgesic and Side-Effects Profiles. British Journal of Anaesthesia, 120, 679-692.

https://doi.org/10.1016/j.bja.2017.11.104

[13] Cancienne, J.M., Brockmeier, S.F., Gulotta, L.V., Dines, D.M. and Werner, B.C. (2017) Ambulatory Total Shoulder Arthroplasty: A Comprehensive Analysis of Current Trends, Complications, Readmissions, and Costs. The Journal of Bone and Joint Surgery. American Volume, 99, 629-637. https://doi.org/10.2106/JBJS.16.00287

[14] Wiesmann, T., Feldmann, C., Müller, H.H., Nentwig, L., Beermann, A., El-Zayat, B.F., et al. (2016) Phrenic Palsy and Analgesic Quality of Continuous Supraclavicular vs. Interscalene Plexus Blocks after Shoulder Surgery. Acta Anaesthesiologica Scandinavica, 60, 1142-1151. https://doi.org/10.1111/aas.12732

[15] El-Boghdadly, K., Chin, K.J. and Chan, V.W.S. (2017) Phrenic Nerve Palsy and Regional Anesthesia for Shoulder Surgery: Anatomical, Physiologic, and Clinical Considerations. Anesthesiology, 127, 173-191. https://doi.org/10.1097/ALN.0000000000001668

[16] Sandefo, I., Bernard, J.M., Elstraete, V., Lebrun, T., Polin, B., Alla, F., et al. (2005) Patient-Controlled Interscalene Analgesia after Shoulder Surgery: Catheter Insertion by the Posterior Approach. Anesthesia \& Analgesia, 100, 1496-1498. https://doi.org/10.1213/01.ANE.0000149901.42804.92

[17] Mahoney, A., Bosco, J.A. and Zuckerman, J.D. (2014) Readmission after Shoulder Arthroplasty. Journal of Shoulder and Elbow Surgery, 23, 377-381. https://doi.org/10.1016/j.jse.2013.08.007

[18] FDA Highlights of Prescribing Information. https://www.accessdata.fda.gov/drugsatfda_docs/label/2018/022496s9lbl.pdf 